\title{
Balkanologie
}

Balkanologie Revue d'études pluridisciplinaires

Vol. IX, n' 1-2 | 2005

Volume IX Numéro 1-2

\section{De Waele (Jean-Michel), éd., European Union accession referendums}

Bruxelles : Éditions de l'Université de Bruxelles, 2005,154 pages.

\section{Emmanuelle Chaveneau-Le Brun}

\section{(2) OpenEdition}

\section{Journals}

Édition électronique

URL : http://journals.openedition.org/balkanologie/1987

DOI : 10.4000/balkanologie. 1987

ISSN : 1965-0582

\section{Éditeur}

Association française d'études sur les Balkans (Afebalk)

Édition imprimée

Date de publication : 1 décembre 2005

ISSN : 1279-7952

\section{Référence électronique}

Emmanuelle Chaveneau-Le Brun, « De Waele (Jean-Michel), éd., European Union accession

referendums », Balkanologie [En ligne], Vol. IX, n 1-2 | 2005, mis en ligne le 14 janvier 2010, consulté le

17 décembre 2020. URL : http://journals.openedition.org/balkanologie/1987 ; DOI : https://doi.org/

10.4000/balkanologie.1987

Ce document a été généré automatiquement le 17 décembre 2020.

(c) Tous droits réservés 


\section{De Waele (Jean-Michel), éd., European Union accession referendums}

Bruxelles : Éditions de l'Université de Bruxelles, 2005,154 pages.

Emmanuelle Chaveneau-Le Brun

\section{RÉFÉRENCE}

De Waele (Jean-Michel), éd., European Union accession referendums, Bruxelles : Éditions de l'Université de Bruxelles, 2005,154 pages.

1 Huit États d'Europe centrale (l'Estonie, la Hongrie, la Lettonie, la Lituanie, la Pologne, la République tchèque, la Slovaquie et la Slovénie) ont posé à tous leurs ressortissants une question identique dans un intervalle de temps inférieur à un an. Il s'agissait de se prononcer sur l'adhésion de leur État à l'Union européenne lors de la dernière vague d'élargissement de la communauté, en mai 2004. Un matériau rare, dont Jean-Michel de Waele s'est saisi, y ajoutant les résultats des élections européennes en juin 2004 et ceux des référendums nationaux sur le projet de Constitution pour l'UE, survenus plus tard.

2 J.-M. De Waele s'interroge dans un premier temps sur la portée politique du référendum en général. Il reprend les arguments ordinaires des pro- et des anti- et les précise dans les contextes politiques nationaux de l'époque où ont eu lieu les referendums pour l'adhésion à l'UE, citant notamment une question de Laurence Morel : «Can a referendum act as an effective remedy to the representational crisis of which it is nowadays a symptom? ». Il estime que les gouvernements d'Europe centrale choisirent de donner au peuple un rôle politique dans leur mouvement de « retour à l'Europe ", tout en espérant gagner du crédit grâce à un oui massif. Les partisans du non n'eurent que de faibles arguments à opposer, si bien que la politisation des votants fut assez faible. Dans un second temps, J.-M. De Waele s'intéresse aux résultats des premières élections européennes qui suivirent d'un mois la vague d'adhésion de mai 2004. Il rappelle les contextes nationaux (périodes politiques d'instabilité dans laquelle se trouvait la plupart des États d'Europe centrale, principaux points de débat par État) 
avant d'en tirer et d'expliquer deux tendances fortes : l'abstention record et le vote de protestation contre les partis au pouvoir. En revanche, il nuance l'idée selon laquelle ce sont les partis eurosceptiques qui ont remporté ces élections.

3 Neuf auteurs analysent ensuite, en huit chapitres dédiés chacun à un pays, les résultats des référendums nationaux pour l'adhésion à l'UE de mai 2004. En une douzaine de pages environ, la situation politique propre à chaque pays est analysée, les résultats mis en lumière par l'étude des partis politiques et autres institutions en présence, de l'évolution de l'opinion publique face à l'élargissement communautaire, voire des clivages internes au pays. Clairs et précis et documentés, chaque article s'appuie sur des figures, tableaux ou graphiques qui peuvent en faire une bonne source pédagogique.

4 Au total, l'ouvrage apporte, dans l'introduction, une comparaison assez succincte des résultats du référendum pour l'ensemble de l'Europe centrale. Mais la juxtaposition des huit analyses nationales extrêmement précises du même événement donne toute latitude à chacun pour cerner les convergences et divergences. 